\title{
A Study of Product Production in Software Product Lines
}

\author{
Gary Chastek \\ Patrick Donohoe \\ John D. McGregor
}

March 2004

Product Line Practice Initiative

Unlimited distribution subject to the copyright.

Technical Note

CMU/SEI-2004-TN-012 
This work is sponsored by the U.S. Department of Defense.

The Software Engineering Institute is a federally funded research and development center sponsored by the U.S. Department of Defense.

Copyright 2004 Carnegie Mellon University.

NO WARRANTY

THIS CARNEGIE MELLON UNIVERSITY AND SOFTWARE ENGINEERING INSTITUTE MATERIAL IS FURNISHED ON AN "AS-IS" BASIS. CARNEGIE MELLON UNIVERSITY MAKES NO WARRANTIES OF ANY KIND, EITHER EXPRESSED OR IMPLIED, AS TO ANY MATTER INCLUDING, BUT NOT LIMITED TO, WARRANTY OF FITNESS FOR PURPOSE OR MERCHANTABILITY, EXCLUSIVITY, OR RESULTS OBTAINED FROM USE OF THE MATERIAL. CARNEGIE MELLON UNIVERSITY DOES NOT MAKE ANY WARRANTY OF ANY KIND WITH RESPECT TO FREEDOM FROM PATENT, TRADEMARK, OR COPYRIGHT INFRINGEMENT.

Use of any trademarks in this report is not intended in any way to infringe on the rights of the trademark holder.

Internal use. Permission to reproduce this document and to prepare derivative works from this document for internal use is granted, provided the copyright and "No Warranty" statements are included with all reproductions and derivative works.

External use. Requests for permission to reproduce this document or prepare derivative works of this document for external and commercial use should be addressed to the SEI Licensing Agent.

This work was created in the performance of Federal Government Contract Number F19628-00-C-0003 with Carnegie Mellon University for the operation of the Software Engineering Institute, a federally funded research and development center. The Government of the United States has a royalty-free government-purpose license to use, duplicate, or disclose the work, in whole or in part and in any manner, and to have or permit others to do so, for government purposes pursuant to the copyright license under the clause at 252.227-7013.

For information about purchasing paper copies of SEI reports, please visit the publications portion of our Web site (http://www.sei.cmu.edu/publications/pubweb.html). 


\section{Contents}

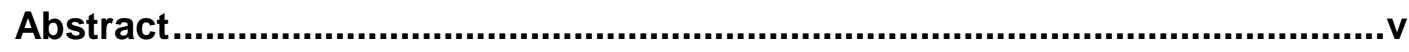

$1 \quad$ Introduction .......................................................................................

1.1 Product Production .......................................................................

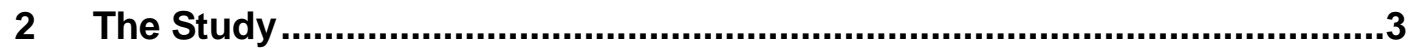

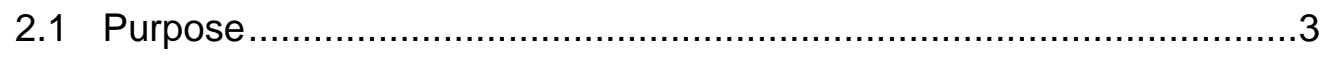

2.2 Digest of Questionnaire Results .................................................

2.2.1 General Information ..................................................

2.2.2 Product Development Information ........................................ 5

2.2.3 Context .......................................................................

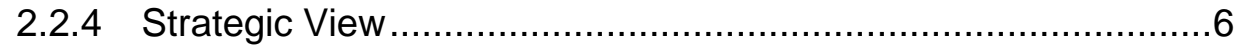

2.2.5 Available Core Assets ..................................................... 8

2.2.6 Detailed Product Production Process.......................................8

2.2.7 Management Information ...............................................

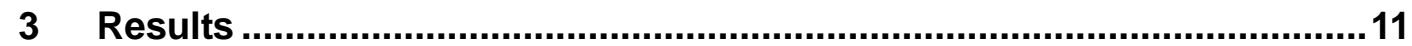

3.1 Preliminary Analysis of Responses ......................................... 11

3.2 Additional Findings ........................................................... 12

3.2.1 Product Production ....................................................... 12

3.2.2 Hierarchical Product Line Definitions....................................12

3.2.3 Production Planning ..................................................... 13

3.2.4 Production Process ...........................................................13

4 Conclusions and Future Directions .................................................... 15

References ......................................................................................... 17 


\section{List of Figures}

Figure 1: Subproduct Lines Within a Product Line..............................................13 


\section{Abstract}

A software product line organization exists to produce products. Much of the research on creating products via product lines has focused on developing core assets such as requirements, architectures, and components. This technical note presents the results of a study that focused on how product line organizations create products (e.g., their production strategy and how core assets are used in the production process). These results include compiled responses to the questionnaire used in the study and follow-up interviews. 


\section{Introduction}

The ultimate goal of a product line organization is to create products efficiently. Much thought and effort goes into the product line architecture and other members of the core asset base. Just as much attention should be focused on how an individual product will be specified and constructed.

Product line organizations have reported using a number of techniques for producing products. Griss reports on the use of aspect-oriented techniques for representing and composing crosscutting features in the creation of a product line [Griss 00]. Batory, Cardone, and Smaragdakis report on the use of object-oriented frameworks and program generators to produce products in a product line [Batory 00]. These papers focus more on the individual production techniques and less on the overall production of products.

While many of the goals for a product line can be achieved primarily through the use of core assets, certain goals — such as decreased time to market — are affected significantly by product production techniques. Given the core asset base, the tools and techniques used to define and assemble a specific product can significantly impact the efficiency and cost of the product line development effort.

This technical note reports on an investigation of actual experience in product production. The responses to a questionnaire and follow-up interviews are discussed and analyzed.

The remainder of this report is organized as follows. Section 1.1 presents the concepts concerning product production and production plans. Section 2 provides some background information on the goals and expectations for the study, and a digest of the responses to the questionnaire. Section 3 analyses questionnaire responses and highlights findings from targeted follow-up interviews that were prompted by those responses. Section 4 discusses conclusions and future directions for product production work, some of which are currently being investigated.

\subsection{Product Production}

A software product line is a set of software-intensive systems sharing a common, managed set of features that satisfy the specific needs of a particular market or mission and that are developed from a common set of core assets in a prescribed way [Clements 02]. A product line is sometimes referred to as a product family. The core asset developers create and maintain the product line core assets, such as the business case, requirements, software architecture, test cases, and so on. The product developers use the core assets to develop the 
specific products in the product line. The production plan $^{l}$ tells product developers how those core assets are applied to build a specific product.

The production plan evolves from the production strategy. That strategy begins as an informal notion in the business case, evolves concurrently with the core assets, and is ultimately documented in the production plan. The production strategy is based on the business goals of the product line and specifies the techniques and conditions for product development that support those goals.

The production strategy is realized in the core assets, their attached processes, and the production plan. The production plan coordinates the efforts of managers, product developers, testers, and clients. It links together the information provided by the product requirements, business case, architecture description, component specifications, asset-use processes, tool support, and other sources such as user manuals. The production plan expands on the Technical Considerations chapter of the Concept of Operations (CONOPS) ${ }^{2}$ by providing a more complete description of the process by which products are created [Cohen 99].

The production plan provides an operational definition of how the organization intends to produce products. The production plan for a product line covers a wider range of topics and is more complex than the typical project plan used by single-product projects. While the exact form and content of the production plan varies from one product line organization to another, the plan is nonetheless a means of communication between the core asset developers and the product developers, as well as a source for resource and schedule estimates. The plan defines the

- inputs needed to build a product

- activities that result in a completed product

- roles and responsibilities of the product developers

- interactions needed with other groups in the organization

- schedule and resources (including tool support) associated with building the product

Sometimes referred to as a reuser's guide

2 The CONOPS document is often used to describe how a computer system will be managed and operated. In product line organizations, the CONOPS describes how the organization operates and helps personnel understand their roles and responsibilities. 


\section{The Study}

\subsection{Purpose}

The primary goal of the study was to document the state of the practice in product production in software product line organizations. In addition, we wished to provide concrete evidence to support the observations in our previous work about product production [Chastek 02a]. We collected data from industry and government product line organizations. Specifically, we invited the attendees of the first and second Software Product Line Conferences [Donohoe 00, Chastek 02b] to complete a questionnaire about various aspects of product production [SEI 03]. The questions were based on the production planning work done by Chastek and McGregor [Chastek 02a]. The ideas contained in that report have been validated through actual use at one of the Carnegie Mellon ${ }^{\circledR}$ Software Engineering Institute's (SEI's) major customer sites.

\subsection{Digest of Questionnaire Results}

We received 22 individual responses. Since not all respondents answered every question, the number of responses for some questions is less than the total number of questionnaire respondents. Conversely, the number of responses to questions that allow multiple answers is sometimes greater than the total number of respondents.

The organization of this section reflects the semantic grouping of questions from the questionnaire. Each subsection includes the question as it appeared in the questionnaire, followed by a brief discussion of the responses to it.

\subsubsection{General Information}

How many years has your company been using a product line strategy?

The responses ranged from 0 to 20 years, with an average experience of just over 5 years.

What is the domain in which your product line(s) produce products (e.g., telecommunications, ground satellite support)?

${ }^{\circledR}$ Carnegie Mellon is registered in the U.S. Patent and Trademark Office by Carnegie Mellon University. 
A variety of domains were reported, including

- military: ground-based air defense and air mission planning, Army training (specifically, instrumented live training), Army command and control, and military command and control

- medical: implantable medical devices, medical imaging equipment, medical information technology, medical imaging, and medical systems

- automotive: embedded power-train control, engine controls, and driver information systems

- training: life and live training

- electronics: semiconductors, consumer electronics, and sensor systems

- miscellaneous: electric and gas utilities; information management, air traffic control, and handheld communication devices; telecommunications; insurance; automated software engineering tools

Is that domain mature? In other words, are the product features relatively stable or are they rapidly changing with each new product?

The majority of the respondents rated their domain as relatively stable, but five rated their domain as highly changeable.

Is product production automatic (products are generated with minimal product developer effort), semi-automatic (products are mostly generated with minimal customization by the product developer), or largely manual (little of the product is generated)?

The majority of the respondents described their product production as semi-automatic, while two described it as automatic and five as largely manual.

Does your organization provide documentation specifically for the product developer? What types of information are supplied to the product developer? What is the form and structure of that information?

While 3 of the respondents stated that no documentation is supplied to the product developers, 16 of the respondents do supply documentation. The forms of that documentation included

- product management plans

- $\quad$ software architectures

- business processes, strategies, and procedures

- technical standards 
- a bill of materials of the core assets

- user guides for the core assets

Has your software process been benchmarked against any standard such as ISO 9000 or the CMM/CMMI? If so, what was the result?

Eleven of the respondents' organizations have been benchmarked against the Capability Maturity Model (CMM) or CMM Integration (CMMI), nine against ISO 9000, and one against the Electronic Industries Alliance (EIA). Five respondents have not benchmarked their software process, while one did not know if his process had been benchmarked.

\subsubsection{Product Development Information}

When do you begin defining how products will be built in the product line?

In our view of successful product line development, product definition begins very early in the product line life cycle, primarily during scoping and business case development. A third of the respondents indicated that they began product definition during business case development, and one respondent defined products during requirements definition. However, the majority began defining the products in their software product line during software architecture definition.

What do you consider to be core assets?

In our view, development artifacts-including software architecture, test cases, documentation, and processes-are core assets. All but one respondent considered the software architecture and code to be core assets. Most respondents considered requirements and tests cases as core assets. However, only three considered documentation as such, and only two considered their process as a core asset.

Are those core assets described in your production plan?

Ten of the respondents documented their core assets in their production plan, while eight did not.

Are the core asset developers and the product developers in distinct groups, or do the same developers create and maintain both the core assets and the products? If they are in distinct groups, please describe the problems that have arisen due to a lack of communication between the core asset developers and the product developers.

Eight respondents placed the core asset and product developers in the same group, 10 placed them in distinct groups, and one reported a hybrid grouping. 
What information is included in the production plan?

The production plans of 12 respondents included a schedule template, 10 included an assembly process, and 8 included a product cost determination algorithm. Other production plan contents included the product approach, management approach, technical services and organization, a process for estimating time and effort, and a quality procedure.

How is your production plan made available to the product developers?

While 11 respondents indicated that they made their production plan available to product developers using an Intranet Web page, 12 used paper documents. Other approaches used included shared directories, presentations, a local network, BigLever Software's GEARS tool, and tools such as Microsoft Excel, Microsoft Project, and Lotus Notes databases.

How is the production plan maintained? How do you deal with the product line evolution, particularly as it affects the production plan?

Four of the respondents specifically mentioned the use of configuration management to control the production plan. Many of the respondents described maintenance of the production plan as a part of an ongoing iterative process, while several indicated that this area needs improvement.

\subsubsection{Context}

Does your organization provide product line context information to the product developer? If so then what types of information are supplied, and how are they supplied?

Thirteen of the responding organizations indicated they provide some form of product line context information (e.g., product line vision, strategy, initial scope, expected benefits) to the product developers, while three do not. Some provided context information that described the position of the product line in the domain. Others provided context information that described the rationale and strategy for the product line.

\subsubsection{Strategic View}

What is the product production strategy of your current product line?

One of our hypotheses was that product line organizations would automate product production where it makes sense in view of the organizational goals and capabilities. All the respondents listed more than one production strategy. Half of them used program generators to build products, while the other half used some form of software templates. All the respondents also used basic integration and development techniques. 
How is that strategy communicated to the product developer?

The two most frequent methods of dissemination were training and documentation. Three of the respondents noted that the strategy was communicated in the product or production plan.

Do the product developers have the same qualifications and background as the core asset developers? What are their job titles?

Fifteen of the respondents indicated that the personnel doing core asset development had the same qualifications as those doing product development. The respondents who acknowledged differences between the groups indicated that they were mainly depth of education and breadth of vision.

When is the software integrated with hardware? When the product is delivered?

With two exceptions, respondents viewed integration as an iterative, ongoing activity regardless of whether special-purpose hardware was involved. Little or no difference was identified for a product line organization. One respondent felt that this was too simplistic a question. Their products contain a variety of hardware and software, and integration occurs at a number of times and places. (Those products operate in a distributed environment and must be tested for such an environment.)

When are variations resolved in your product line?

Product line organizations resolve variation at many points. Respondents were given a choice of design, compile, install, or run times. The vast majority, 20 and 19 respondents

respectively, resolved variation at design time and compile time. Eleven of those respondents resolved variation at all four points.

Where does most of the binding of variation points occur?

Product line organizations use a wide variety of binding times. Two respondents indicated that this was a difficult question to answer because of the many places where binding occurs. Another respondent indicated that load time and various levels of installation time were omitted from the survey. Interestingly, four respondents bind only at compile time.

What effect, if any, have you seen on the production strategy/plan as a result of handling variation at these points in the product development flow?

One respondent wrote, "Management of variation is probably the most significant factor in the design of the production strategy/plan." Four respondents saw no effect and one wasn't sure. Other comments supported conventional wisdom: 
- "Variations must be well documented and visible to the product developers to avoid costly rework."

- 'If you haven't anticipated all the variability you need, you pretty much can't avoid going back through domain engineering and correcting this there. Quick-fix hacks can work for a little while, but are big problems if they aren't handled properly pretty quickly."

- "Runtime configurable options have been a major source of improvement in time to market and stability and flexibility of the product."

\subsubsection{Available Core Assets}

How are the core assets made available to the product developers?

Twelve respondents said that core assets are made physically available via a searchable repository. Others reported less formal channels, including a catalog, a course or tutorial, asset experience gained on previous projects, and word of mouth.

Describe any other information that the core asset developers currently provide to product developers to help them build products. How has that information changed as the product line has matured?

Respondents listed different types of information that are provided about the core assets, including information about the range of variations possible in a specific asset and guidance on tuning a product. Other information is provided to the product developers by the core asset developers in the form of peer reviews and working groups; guidelines and coding standards; initiatives involving the business-object modeling of requirements using the Unified Modeling Language (UML) and automated analysis of models; specifications and design; workshops; and problem report and change request databases.

\subsubsection{Detailed Product Production Process}

Is there a formal product production process definition?

The respondents were evenly split on whether they have a formal production planning process. Four respondents felt they had some process, but a less mature one than needed. Several consider their production process to be proprietary and so were unable to disclose any details without a nondisclosure agreement.

How does the product production process relate to the organization's overall software development process? 
Three respondents saw no difference between the two processes. Four respondents saw the product production process as a subprocess of the software development process. Three saw the two processes as related but separate from each other.

\subsubsection{Management Information}

What metrics have proven successful in quantifying the production process?

Several respondents have no metrics for quantifying their product production process. The others listed various metrics, some of which were identical to those commonly used in software development efforts. These metrics included

- $\quad$ source lines of code (SLOC)

- cost

- productivity

- quality (errors and defects)

- $\quad$ effort

- open and resolved problem reports

- effectiveness curve for new engineers

- change request metrics

Other identified metrics are unique to a software product line development effort, including

- number of products created

- levels of reuse

- ratio of variability to commonality (in code and requirements)

- function points for core assets

- time to market per product

- number of products produced per month

Have the initial expectations of the product line been met?

The majority of respondents (13) felt that the product line approach had largely or completely met their expectations. Six respondents either had set no specific expectations or had not yet evaluated whether their expectations had been met. Only three felt their expectations had not been met. 
Has the production of products been as efficient and inexpensive as initially expected?

Most respondents felt it was too soon in their use of the product line approach to say much about benefits. One respondent said that the assets took longer to develop and cost more than expected. Another respondent indicated that the efficiency and cost of his/her product lines varied and that some product lines did not result in profit. One respondent believed that his/her company could reduce the number of assets needed to create a product, but because the appropriate managers were not yet convinced, the company was not benefiting from the product line approach. 


\section{Results}

We report on two kinds of results below:

1. the direct results obtained from examining the questionnaire responses. These results are reported in terms of the correlation between product line success and specific characteristics of the reporting organization (e.g., domain experience).

2. additional findings arising from follow-up interviews with specific respondents

\subsection{Preliminary Analysis of Responses}

In this section, we consider relationships among certain aspects of product production. Using the questionnaire responses reported in Section 2.2, we explored relationships between the answers to one question and those for another. Due to the small sample size, we used chisquare contingency tables. The "Expected" dimension of the table was based on a hypothesized relationship between the concepts measured by two questions. The actual questionnaire responses made up the "Actual" dimension of the table. In the descriptions below, we indicate which of those comparisons indicated a statistically significant result. For those comparisons, we include the level of confidence in that relationship.

As mentioned in the previous section, a majority of the questionnaire respondents felt that the product line approach had largely or completely met their expectations. An analysis of the responses indicated that there is a positive correlation between a product line's being reported as having met expectations and several other responses, including

- experience in the domain: There was a positive correlation, but the relationship did not reach statistical significance. This does (weakly) support the common notion that domain issues (e.g., experience in, leadership in, and stability of the domain) play a major role in product line practice. Additional analysis shows a statistically significant relationship between a product line having met expectations and the stability of the domain within which the product line resides.

- use of separate core asset and product development teams: The relationship between meeting expectations and having separate teams for core asset development and product production was significant at the .001 level. This result seems to indicate that the two roles are difficult to manage in a single team.

- whether the two groups have the same qualifications: This relationship between meeting expectations and members of core asset and product teams having the same qualifications was statistically significant at the .001 level. It may indicate that having highly qualified staff in both roles aids in meeting expectations. 
- when product definition begins: Dividing the answers into two categories - early and late — created a statistically significant relationship at the .01 level between beginning product definition early and having the product line meet expectations.

\subsection{Additional Findings}

The analysis of the questionnaire responses raised several questions. Since several respondents to the questionnaire had indicated a willingness to be contacted, we asked a few of them additional questions. Their responses may not be representative of the group as a whole and are offered as descriptive information only.

\subsubsection{Product Production}

The interviews confirmed, through the experience of the respondents, certain basic notions.

- Core assets cost approximately 50\% more effort to produce than non-reusable assets.

- Even an organization that was achieving 70-80\% reuse can expect to increase that amount using the product line approach.

- Time-to-market goals continue to be achieved. One respondent built one product in one year and then seven products in the first six months of the next year.

\subsubsection{Hierarchical Product Line Definitions}

The interviews brought up the issue of relationships among product lines and the concept of a subproduct line. Some of the respondents used a commonality and variability approach to define the differences between products within a product line. Two respondents used the concept of subproduct lines where the differences among sets of products outweighed the commonality. As shown in Figure 1, a certain amount of asset reuse occurs across the entire product line. However, the degree of reuse, as indicated by the thickness of the arrow, is much higher among products within the same subproduct line.

Following up on responses to the questions about variations and production strategy, we identified two different approaches being used to identify and design products:

1. Perform a commonality and variability analysis of the domain or domains. In this approach, the choices possible at a variation point indicate possible different products. All possible combinations of choices at all variation points define all possible products. The organization then selects certain combinations to build as products.

2. Construct product requirements for a desired set of products. These requirements are grouped into various subsets based on shared requirements. Sets of products that share a large number of these subsets are viewed as a subproduct line within the overall product line. 
The choice of approach seems to be related to the breadth of vision of the organizational unit defining the product line. If the unit is at, or near, the top of the organization, the breadth of products is likely to be similar to the outer oval in Figure 1. If the unit is a "product group" within a larger organization, the view is probably restricted to one of the internal ovals. In a sense, one level of scoping ${ }^{3}$ has already been done by the organization.

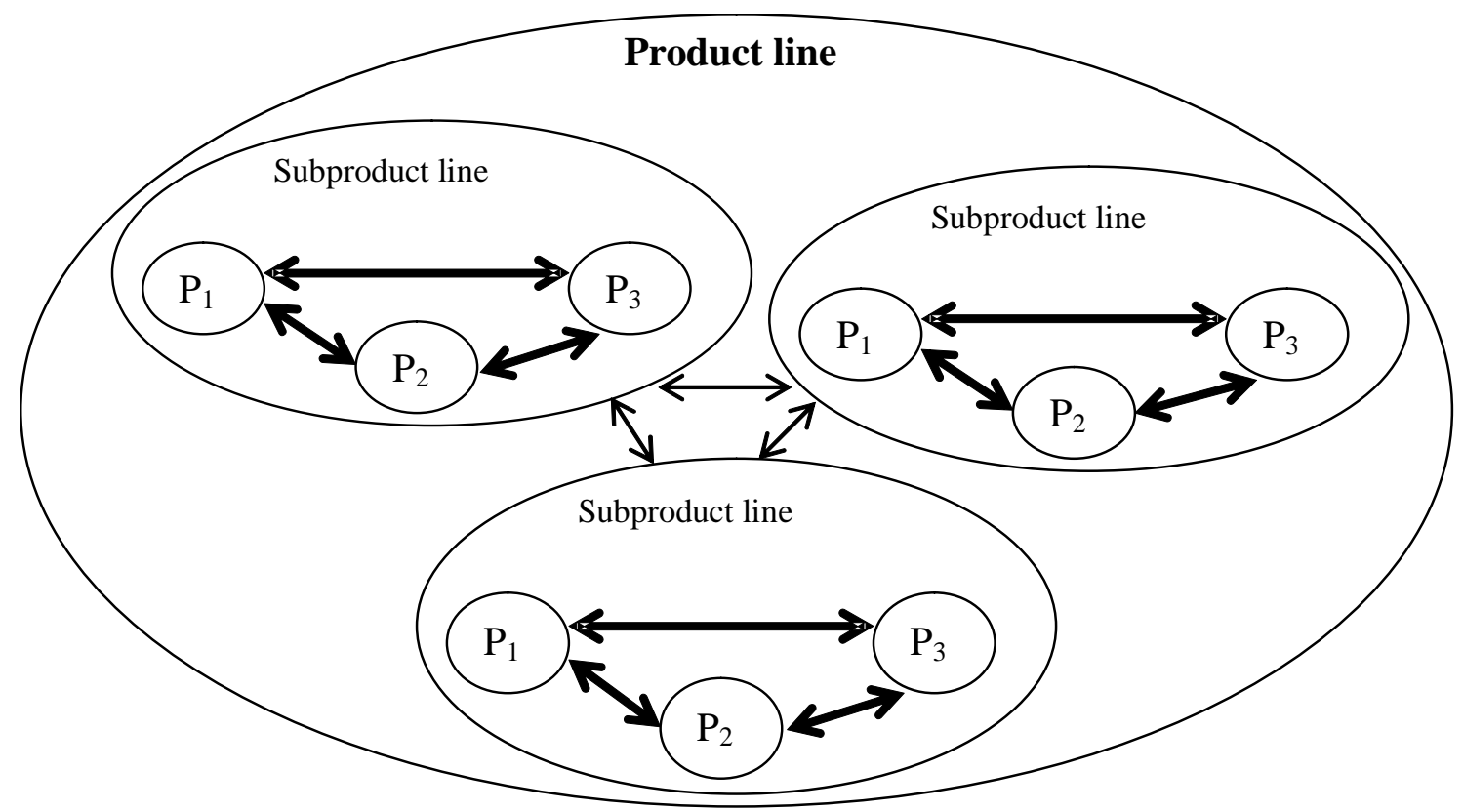

Figure 1: Subproduct Lines Within a Product Line

\subsubsection{Production Planning}

One of the follow-up interviews reinforced the necessity of early production planning. This respondent, a veteran of two product lines, had learned from experience the problems that can arise if production planning is put off.

\subsubsection{Production Process}

An interesting hybrid approach to creating a production process was elicited during the interviews. In this approach, an infrastructure is created up front that provides commonality among all the subproduct lines. When the first product in the subproduct line is constructed, the infrastructure is used to define a production process for the products within that group.

3 Scoping is the activity that bounds the product line by defining what's "in" and what's "out." The goal of scoping is to define this boundary so the chosen set of products will be profitable. For more information, see the Scoping practice area of A Framework for Software Product Line Practice [Clements 04]. 
This approach implicitly assumes that products within the subproduct line share common characteristics such as variation resolution and binding times. 


\section{Conclusions and Future Directions}

The data collected in this research helped us to achieve the goals of the study. The diversity of the domains and the range of the respondents' experience levels ensure that the responses on the questionnaire are representative of software product line organizations. In addition, the data enabled us to validate several of the relationships described in our previous work. And, of course, we identified some remaining challenges that are described below.

The responses yielded several interesting results. In particular, the data illustrated the diversity of approaches being followed in product line organizations with regard to production planning. As discussed in the previous section, we analyzed some aspects of those approaches and identified certain relationships among them. These results identified certain practices as successful with respect to a product line's meeting its expectations.

The data also illuminated some areas that require further investigation. Our future research will attempt to develop or identify successful practices in these areas. Some of the issues to be addressed, in so far as they provide insight into product production, are the following:

- There is no standard vocabulary for discussing product production in a software product line. The wide range of responses to some questions led us to provide more complete definitions and to expect more diversity in the answers. Our future research will include a domain model of product production to which various approaches and terminology can be mapped.

- Product line organizations use a wide range of variation resolution and definition binding times, often within a single product line. Our future research will attempt to more completely capture and analyze the range and the flexibility that variability and binding decisions bring to product production.

The results of the study also highlighted areas in which further research by the product lines community would be useful:

- The management and evolution of the production plan is not well understood. This is part of the larger concern about evolution, which we have previously addressed [McGregor 03].

- The relationship between the software development process and the product production process is complex and not well understood. There is a need for research into the appropriate processes and relationships among these processes. This research would investigate how to differentiate between component development processes and component integration processes. 


\section{References}

URLs are valid as of the publication date of this document.

[Batory 00] Batory, Don; Cardone, Rich; \& Smaragdakis, Yannis. "ObjectOriented Frameworks and Product Lines," 227-247. Software Product Lines: Experience and Research Directions. Proceedings of the First Software Product Line Conference (SPLC1). Denver, Colorado, August 28-31, 2000. Boston, MA: Kluwer Academic Publishers, 2000.

[Chastek 02a] Chastek, G. \& McGregor, J. Guidelines for Developing a Product Line Production Plan (CMU/SEI-2002-TR-006, ADA407772). Pittsburgh, PA: Software Engineering Institute, Carnegie Mellon University, 2001. http://www.sei.cmu.edu/publications/documents /02.reports/02tr006.html

[Chastek 02b] Chastek, G., ed. Software Product Lines: Second International Conference (SPLC2). Lecture Notes in Computer Science, Vol. 2379. San Diego, California, August 19-22, 2002. New York, NY: Springer, 2002.

[Clements 02] Clements, Paul \& Northrop, Linda. Software Product Lines: Practices and Patterns. Boston, MA: Addison-Wesley, 2002.

[Clements 04] Clements, Paul \& Northrop, Linda. A Framework for Software Product Line Practice, V4.2. http://www.sei.cmu.edu/plp /framework.html (2004)

[Cohen 99]

Cohen, Sholom. Guidelines for Developing a Product Line Concept of Operations (CMU/SEI-99-TR-008, ADA367714). Pittsburgh, PA: Software Engineering Institute, Carnegie Mellon University, 1999. http://www.sei.cmu.edu/publications/documents/99.reports /99tr008/99tr008abstract.html 
[Donohoe 00]

[Griss 00]

[McGregor 03]

[SEI 03]
Donohoe, Patrick, ed. Software Product Lines: Experience and

Research Directions. Proceedings of the First Software Product Line Conference (SPLC1). Denver, Colorado, August 28-31, 2000.

Boston, MA: Kluwer Academic Publishers, 2000.

Griss, Martin. "Implementing Product-Line Features by Composing Aspects," 271-288. Software Product Lines: Experience and Research Directions. Proceedings of the First Software Product Line Conference (SPLC1). Denver, Colorado, August 28-31, 2000. Boston, MA: Kluwer Academic Publishers, 2000.

McGregor, John. The Evolution of Product Line Assets (CMU/SEI2003-TR-005, ADA418409). Pittsburgh, PA: Software Engineering Institute, Carnegie Mellon University, 2003.

http://www.sei.cmu.edu/publications/documents/03.reports /03tr005.html

Software Engineering Institute. http://www.sei.cmu.edu/plp /production_questionnaire.html (2004) 


\begin{tabular}{|c|c|c|c|c|}
\hline \multicolumn{3}{|c|}{ REPORT DOCUMENTATION PAGE } & \multicolumn{2}{|c|}{$\begin{array}{l}\text { Form Approved } \\
\text { OMB No. 0704-0188 }\end{array}$} \\
\hline \multicolumn{5}{|c|}{ 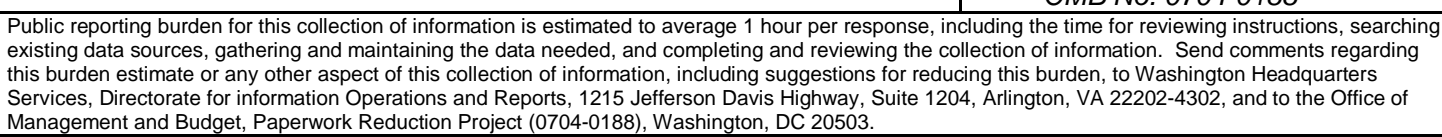 } \\
\hline $\begin{array}{l}\text { 1. AGENCY USE ONLY } \\
\text { (Leave Blank) }\end{array}$ & \multicolumn{2}{|c|}{$\begin{array}{ll}\text { 2. REPORT DATE } \\
\text { March } 2004\end{array}$} & \multicolumn{2}{|c|}{$\begin{array}{l}\text { 3. REPORT TYPE AND DATES COVERED } \\
\text { Final }\end{array}$} \\
\hline \multicolumn{3}{|c|}{$\begin{array}{ll}\text { 4. } & \text { TILEANDSUBTTLE } \\
& \text { A Study of Product Production in Software Product Lines }\end{array}$} & \multicolumn{2}{|c|}{$\begin{array}{ll}5 . & \text { FUNDING NUMBERS } \\
& \text { F19628-00-C-0003 }\end{array}$} \\
\hline \multicolumn{5}{|c|}{$\begin{array}{ll}\text { 6. } & \text { AUTHOR(S) } \\
& \text { Gary Chastek, Patrick Donohoe, }\end{array}$} \\
\hline \multicolumn{3}{|c|}{$\begin{array}{l}\text { 7. PERFORMNG ORGANZATIONNAME(S) AND ADDRESS(ES) } \\
\text { Software Engineering Institute } \\
\text { Carnegie Mellon University } \\
\text { Pittsburgh, PA } 15213\end{array}$} & \multicolumn{2}{|c|}{$\begin{array}{ll}\text { 8. } & \text { PERFORMNG ORGANZATON } \\
\text { REPORT NUMBER } \\
\text { CMU/SEI-2004-TN-012 }\end{array}$} \\
\hline \multicolumn{3}{|c|}{$\begin{array}{l}\text { 9. SPONSORING/MONTORING AGENCY NAME(S) AND ADDRESS(ES) } \\
\text { HQ ESC/XPK } \\
5 \text { Eglin Street } \\
\text { Hanscom AFB, MA 01731-2116 }\end{array}$} & \multicolumn{2}{|c|}{$\begin{array}{l}\text { 10. SPONSORING/MONTORING AGENCY } \\
\text { REPORT NUMBER }\end{array}$} \\
\hline \multicolumn{5}{|l|}{ 11. SUPPLEMENTARY NOTES } \\
\hline \multicolumn{3}{|c|}{$\begin{array}{l}\text { 12A DISTRIBUTIONAVALABIUTYSTATEMENT } \\
\text { Unclassified/Unlimited, DTIC, NTIS }\end{array}$} & \multicolumn{2}{|c|}{ 12B DISTRABUTONCODE } \\
\hline \multicolumn{5}{|c|}{$\begin{array}{l}\text { 13. ABSTRACT (MAXIMUM 200 WORDS) } \\
\text { A software product line organization exists to produce products. Much of the research on creating products } \\
\text { via product lines has focused on developing core assets such as requirements, architectures, and } \\
\text { components. This technical note presents the results of a study that focused on how product line } \\
\text { organizations create products (e.g., their production strategy and how core assets are used in the production } \\
\text { process). These results include compiled responses to the questionnaire used in the study and follow-up } \\
\text { interviews. }\end{array}$} \\
\hline \multicolumn{3}{|c|}{$\begin{array}{l}\text { 14. SUBJECT TERMS } \\
\text { software product line, production planning }\end{array}$} & \multicolumn{2}{|c|}{$\begin{array}{l}\text { 15. NUMBER OF PAGES } \\
26\end{array}$} \\
\hline \multicolumn{5}{|l|}{ 16. PRICE CODE } \\
\hline $\begin{array}{l}\text { 17. SECURTYYCLASSIFCATION } \\
\text { OF REPORT } \\
\text { Unclassified }\end{array}$ & $\begin{array}{l}\text { 18. SECURTY CLASSIFCATONOF } \\
\text { THS PAGE } \\
\text { Unclassified }\end{array}$ & $\begin{array}{l}\text { 19. SECURTYYCLA } \\
\text { ABSTRACT } \\
\text { Unclassifie }\end{array}$ & SIFCATION OF & $\begin{array}{l}\text { 20. LMTATION OF ABSTRACT } \\
\text { UL }\end{array}$ \\
\hline
\end{tabular}

